\title{
Isolated bilateral limbal dermoid, preauricular skin tags and ametropic amblyopia
}

\author{
Aarzoo Juneja, ${ }^{1}$ Athul Suresh Puthalath (D) , 1 Neeti Gupta, ${ }^{1}$ \\ Prashant Kumar Verma (D) ${ }^{2}$
}

${ }^{1}$ Ophthalmology, All India Institute of Medical Sciences - Rishikesh, Rishikesh, Uttarakhand, India ${ }^{2}$ Paediatrics, All India Institute of Medical Sciences - Rishikesh, Rishikesh, India

Correspondence to Dr Neeti Gupta; drneetigupta@rediffmail.com

Accepted 1 July 2021
Check for updates

(c) BMJ Publishing Group Limited 2021. No commercial re-use. See rights and permissions. Published by BMJ.

\begin{tabular}{l}
\hline To cite: Juneja A, \\
Puthalath AS, Gupta N, \\
et al. BMJ Case Rep \\
2021;14:e245078. \\
doi:10.1136/bcr-2021- \\
245078 \\
\hline
\end{tabular}

\section{DESCRIPTION}

The parents of a 7-year-old boy reported to the ophthalmology clinic with complaints of a mass in both eyes of the child, noticed since birth, which had gradually increased in size. Antenatal, birth and family history were insignificant. On ocular evaluation, the best uncorrected visual acuity in the right and left eyes were 20/600 and 20/80, respectively. After undergoing refraction with +6.00 dioptre spherical, -3.00 dioptre cylindrical $\left(60^{\circ}\right)$ in the right eye and +2.50 dioptre spherical, -2.00 dioptre cylindrical $\left(160^{\circ}\right)$ in the left eye, the child had a best-corrected visual acuity of 20/200 and $20 / 60$ in the right eye and left eye, respectively. Anterior segment evaluation revealed a solid pale ovoid mass with a few hair follicles located at the inferotemporal limbus of both eyes between 6-9 o'clock in the right eye and 3-5 o'clock in the left eye (figure $1 \mathrm{~A}-\mathrm{C}$ ). The masses measured $1.5 \mathrm{~cm} \times$ $2 \mathrm{~cm}$ and $1 \mathrm{~cm} \times 1 \mathrm{~cm}$ in the right and left eyes, respectively, and did not obstruct the visual axes. Anterior segment optical coherence tomography (AS-OCT) showed grade 2 limbal dermoid in both eyes. ${ }^{1}$ The rest of the anterior and posterior segment ocular examinations of both eyes were within normal limits. On detailed systemic evaluation, the patient was found to have bilateral asymmetrical preauricular skin tags without any microtia, fistula or hearing loss. There was no facial asymmetry, no vertebral anomaly or any other systemic abnormalities. A diagnosis of Goldenhar syndrome (GS)

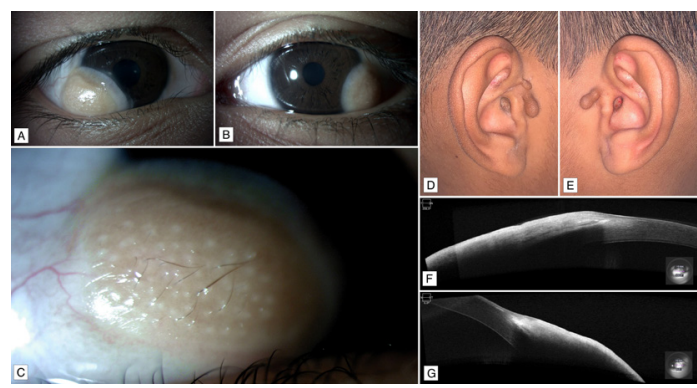

Figure 1 Diffuse slit lamp images of the right eye (A) and the left eye (B) showing epibulbar limbal dermoid located inferotemporally. (C) High magnification view of the dermoid showing hair follicles with hair. Preauricular tags with normal appearing pinnae seen on the right side (D) and left side (E). Anterior segment optical coherence tomography through the dermoid-corneal junction of the right eye (F) and the left eye (G) showing invasion into the corneal stroma but not involving the Descemet's membrane. with bilateral ametropic amblyopia was made. The child was provided spectacle correction and advised patch therapy for amblyopia. The father declined the option for surgical excision of the dermoid due to the COVID-19 pandemic.

GS is a spectrum called craniofacial microsomia, having a triad of hemifacial microsomia, ear and ocular involvement and vertebral anomalies. ${ }^{2}$ Most characteristically, the structures derived from the first and second branchial arch are affected around day 30-35 due to vascular disturbance or neural crestopathy. ${ }^{3}$ GS is usually sporadic and has asymmetrical facial involvement, with the right side more affected than the left. ${ }^{2}$ Ear anomalies (which vary from anotia to preauricular tags) and hemifacial microsomia both have the same prevalence of $80-99 \%$ in GS, while vertebral abnormalities are usually present in $40-60 \%$ of cases. ${ }^{245}$ It is seen that $30-60 \%$ of patients have ocular involvement, which can be anophthalmia, microphthalmia, blepharophimosis, epibulbar tumours, strabismus, upper lid coloboma, epicanthal folds, lacrimal drainage abnormality, glaucoma and retinal abnormalities. ${ }^{6}$

\section{Patient's perspective}

My son has a whitish swelling in both eyes since birth which is increasing in size. He also developed gradual reduction of vision as he grew up. After a complete evaluation of my son, the eye doctor informed me regarding the disease he may have. My son was also evaluated by other doctors from various other departments as well. He was given spectacle correction and was also advised to have surgery to remove the swelling in both eyes. I have decided to bring my son for the surgery at a later date due to the COVID-19 pandemic.

\section{Learning points}

Although hemifacial microsomia and vertebral malformation are frequently associated with Goldenhar syndrome, patients may also present with auricular and ocular features alone.

- AS-OCT can be used to grade the extent of dermoid in the anterior segment, which can guide further management.

- Refractive correction and amblyopia therapy should be initiated as soon as possible to prevent further visual deterioration. 
Epibulbar dermoid are seen in about 39\% of cases, of which $10-25 \%$ cases are bilateral. ${ }^{78}$ Preauricular skin tags are most often clinically insignificant and, thus, reassurance is the only treatment required in the absence of other signs or symptoms. The cause of reduction in vision is either due to direct obscuration of the visual axis by the dermoid or to astigmatism induced by them. The child had developed amblyopia due to uncorrected refractive error as a result of against the rule astigmatism caused by the limbal dermoid. He had grade 2 limbal dermoid on ASOCT as they were more than $5 \mathrm{~mm}$ in size and also were seen invading into the corneal stroma without involving the Descemet's membrane. ${ }^{19}$ Grade 2 dermoid can be treated by keratectomy followed by amniotic membrane transplantation. ${ }^{9}$ Early ophthalmologic intervention for visual rehabilitation is of utmost importance.

\section{Twitter Athul Suresh Puthalath @asputhalath}

Acknowledgements We acknowledge the patient and the residents of the Department of Ophthalmology of our institute.

Contributors AJ: review of literature, drafting of the manuscript, approval of the final version of the manuscript. ASP: data acquisition, data analysis, drafting of the manuscript, approval of the final version of the manuscript. NG: conception of study, data interpretation, drafting and critical revision of the manuscript, approval of the final version of the manuscript. PKV: conception and design of the study, data interpretation, drafting of the manuscript, approval of the final version of the manuscript.
Funding The authors have not declared a specific grant for this research from any funding agency in the public, commercial or not-for-profit sectors.

Competing interests None declared.

Patient consent for publication Parental/guardian consent obtained.

Provenance and peer review Not commissioned; externally peer reviewed.

\section{ORCID iDs}

Athul Suresh Puthalath http://orcid.org/0000-0002-0483-7014

Prashant Kumar Verma http://orcid.org/0000-0001-8929-5017

\section{REFERENCES}

1 Tiwari U, Kujur R, Paul R, et al. Anterior segment optical coherence tomography (ASOCT) in Goldenhar syndrome. J Clin Ophthalmol Res 2014;2:159-60.

2 Schmitzer S, Burcel M, Dăscălescu D, et al. Goldenhar syndrome - ophthalmologist's perspective. Rom J Ophthalmol 2018;62:96-104.

3 Goswami M, Bhushan U, Jangra B. Goldenhar syndrome: a case report with review. Int J Clin Pediatr Dent 2016;9:278-80.

4 Tasse C, Böhringer S, Fischer S, et al. Oculo-auriculo-vertebral spectrum (OAVS): clinical evaluation and severity scoring of 53 patients and proposal for a new classification. Eur $J$ Med Genet 2005:48:397-411.

5 Avon SW, Shively JL. Orthopaedic manifestations of Goldenhar syndrome. J Pediatr Orthop 1988:8:683-6.

6 Bhallil S, Benatiya I, El Abdouni O, et al. Goldenhar syndrome: ocular features. Bull Soc Belge Ophtalmol 2010;316:17-19.

7 Shrestha UD, Adhikari S. Craniofacial microsomia: Goldenhar syndrome in association with bilateral congenital cataract. Case Rep Ophthalmol Med 2015;2015:1-3.

8 Bayraktar S, Bayraktar ST, Ataoglu E, et al. Goldenhar's syndrome associated with multiple congenital abnormalities. J Trop Pediatr 2005;51:377-9.

9 Pirouzian A. Management of pediatric corneal limbal dermoids. Clin Ophthalmol 2013;7:607-14.

Copyright 2021 BMJ Publishing Group. All rights reserved. For permission to reuse any of this content visit

https://www.bmj.com/company/products-services/rights-and-licensing/permissions/

BMJ Case Report Fellows may re-use this article for personal use and teaching without any further permission.

Become a Fellow of BMJ Case Reports today and you can:

- Submit as many cases as you like

- Enjoy fast sympathetic peer review and rapid publication of accepted articles

- Access all the published articles

- Re-use any of the published material for personal use and teaching without further permission

Customer Service

If you have any further queries about your subscription, please contact our customer services team on +44 (0) 2071111105 or via email at support@bmj.com.

Visit casereports.bmj.com for more articles like this and to become a Fellow 